\title{
Spousal Conflict Style, Support and Negativity: Impact on Children's Social Competence
}

\author{
Michael Van R Slyck ${ }^{1 *}$, Sara K Moritzen ${ }^{2}$ and Marilyn Stern ${ }^{3}$ \\ ${ }^{1}$ South University, USA \\ ${ }^{2}$ University at Albany, USA \\ ${ }^{3}$ University of Southern Florida, USA
}

Submission: June 06, 2018; Published: August 09, 2018

*Corresponding author: Dr. Michael R Van Slyck, PhD, Associate Professor of Psychology Director, Psychology Program, South University, Georgia, USA, Email: mvanslyck@southuniversity.edu

\begin{abstract}
Previous research examining the relationship between spousal conflict behavior and children's social competence delineated two conflict management styles-hot positive and cold negative. The former had a positive relationship with children's social competence and the latter a negative relationship. The authors of the study called for additional research to examine the relationship of conflict management style and other relevant factors with child outcomes. The research reported here examined the degree to which spouses' conflict management style assessed on five dimensions, and such factors as social support and negativity within the marital relationship related to children's social competence.A hierarchical regression analysis indicated that this constellation of factors predicted children's social competence.In addition, a correlational analysis revealed some strong relationships among conflict style, coping behavior and child outcomes.The results of this study extend the findings of earlier research by demonstrating a relationship among conflict management style, general coping skills and overall emotional climate between the spouses. Family conflict practitioners might use these results to help spouses understand how their conflict behavior affects their children's developmental outcomes.
\end{abstract}

\section{Introduction}

\section{Spousal conflict management style, support and nega- tivity}

Factors affecting children's social competence: To state the obvious, parents are usually young children's primary source of learning experiences, and therefore one of the most important influences in a child's social adjustment.Moreover, because social modeling is one of the most powerful modes of learning [1], children's peer adjustment may well reflect what they see in their parents' marital relationship. Indeed, observing children's play, [2]noted that, "The quality of the peer interaction more closely resembles that of the marital interaction than of the parent-child interaction".

One of the most important areas of social interaction which modeling may influence is that of the management of interpersonal conflict. Research suggests that children's behavior may not reflect the frequency or intensity of spousal conflict so much as the quality of behaviors used in response to the conflict [3]. Cummings and Watson, for example, found that children's emotional security was associated with specific perceptions of their parents' conflict, e.g., whether the conflict was resolved versus unresolved, whether it centered on adult problems versus child problems, and whether the parents explained the conflict. Not surprisingly, children were less secure when parents described their conflict as destructive than when it was explained as constructive arguing.Katz \& Gottman [2]identified two sets of behaviors used by couples in conflict.

So, called "Hot/Positive" couples confront rather than avoid conflict, make frequent eye contact, focus on the problem, are clear about boundaries, interject positive comments and display positive feelings toward each other while engaged in an argument. "Cool withdrawn" couples, on the other hand, tend to engage in less proactive conflict management behaviors, instead avoiding or withdrawing from the conflict. Evading overt disagreement, they express displeasure, disgust, contempt, or disapproval toward each other nonverbally.

In $[4,5]$ studies, children's problematic behaviors were closely associated with their parents' spousal interactions. Specifically, the level of hostility in the parents' conflict predicted children's externalizing behaviors as reported by teachers, and the level of withdrawal in parents' conflict predicted teacher-reported 
anxiety and social isolation. Interacting with their parents, the children of hot and positive couples used humor, whereas the children of cool and withdrawn couples tended to be sad. With their peers, the latter group lacked positive affect, displayed frustration, had minimal involvement, and was unable to find common ground.

In addition, longitudinal studies show that parents' conflict management styles have a long-term effect on children's adjustment and behavior, specifically on their academic achievement and the quality of their peer interactions [5]. In calling for further research [2,5] suggested taking a more nuanced approach to the examination of conflict management styles as well as examining other potentially relevant factors. To accomplish the former goal, we invoked models of conflict management from what can be characterized as main stream social conflict theory [6].

This approach to understanding conflict attempts to describe the nature, genesis and process of interpersonal conflicts.One important aspect of this approach is the delineation of sets of conflict management styles as well as the motivational basis for their use.One such set of styles suggests that different behaviors reflect the ratio of concern for one's own interests versus for those of the other person $[7,8]$. This model suggested itself as relevant to the spousal relationship and associated interactions around the issue of conflict.

In this model, five response modalities or styles are posited: avoidance, accommodation, cooperation, compromise and contention, each reflecting, simultaneously, greater or lesser concern both for one's own needs and interests as well as those of the other in the conflict.Finally, in this regard, it can be noted that while the degree to which a specific conflict behavior is functional often depends on situational factors (e.g., consider the effectiveness of attempting to coerce a young child versus one's boss), people tend to behave consistently in a variety of social contexts which might in fact call for different conflict management styles [8]. Based on this model and on $[2,5]$ work, we differentiated positive conflict resolution (PCR) from negative conflict resolution (NCR) behaviors. PCR tactics include integrating (negotiating and problem solving) and compromising, both of which express a moderate to high concern for self and other.

NCR tactics include accommodating (acknowledging another's authority and attempting to please that person), avoiding (disengaging, distracting, and withdrawing), and contending (using legitimate authority, illegitimate force, or coercion; [7]. These latter behaviors reflect a low (avoiding) or unbalanced (contending, accommodating) concern for self and other.Clearly elements of affect can be inferred from some of the conflict management styles described (e.g., the use of contention should evoke negative affect, while engagement in cooperation is likely to be related to positive affect).
However, in general, conflict resolution theorists, tend to only consider the behaviors people use during interpersonal conflicts, and not focus on the affective quality of the relationships themselves. Therefore, to more fully reflect the hot versus cool distinction in [2,4] typology, we also investigated spousal support [4] and negativity [9] directly. Spousal social support, which refers to encouraging positive self-appraisal, confirming self-concept and self-worth, and feeling emotionally accepted and valued, reflects the attitudes and behavior of hot and positive couples, which validate each other and use positive comments and humor during conflicts.

Spousal negativity, on the other hand, which refers to expressing dislike and negative appraisal of the other's value, worth, and actions, reflects the attitudes and behavior of cool and withdrawn couples, which use disapproving, contemptuous, and denigrating remarks during conflicts. In this context, we predicted that children exposed to marital conflicts in which their parents used relatively more positive conflict tactics and fewer negative tactics to resolve their disputes would be viewed and rated as more socially competent.In addition, we predicted that the marital relationships in such families would be relatively more socially supportive and relatively less emotionally negative.

\section{Method}

\section{Participants}

We randomly selected 66 participants from an available, non-clinical sample from a larger unrelated study $(\mathrm{N}=98)$. The subjects were mothers who lived with the father of at least one child between the ages of 6 and 11. Because some research suggests gender differences in how men and women approach conflict (e.g., [2] and perceive social support Lepore, we focused on only one gender-the female. The sample included European American (80.3\%), Asian/Asian American/Pacific Islander (10.6\%), African American (9.1\%) women, 90.9\% of whom were married for $\mathrm{M}=13.5$ years, $\mathrm{SD}=6.1$. The modal respondent was 37 years old $(M=38.4, S D=6.8)$, with two children $(M=2.3$, $\mathrm{SD}=1.1)$, was college educated $(65.1 \%)$, and worked outside the home $(89.4 \%)$, with an annual income of $\$ 60,000$ or more $(65.2 \%)$

\section{Instruments}

\section{Demographic questionnaire}

A demographic sheet asked participants' age, race or ethnicity, educational level, annual household income, marital status; number, ages, and gender of children, and questions about living arrangements with the target child and his or her father. Additional items inquired about the target child's age, gender, and grade in school, and frequency of marital disagreements over the past six months.

\section{Child behavior checklist}

Participants were asked to complete the 20-item social competence scale in the 138-item school-aged version of the 
Child Behavior Checklist \{CBCL [10] for their youngest child between the ages of 6 and 11. Many studies have found the CBCL to be a valid and reliable measure of children's behaviors [11-13]. The social competence scale operationalizes children's social adjustment in three domains: activities (e.g., chores, sports), social involvement, and school performance and problems [1113].

Scored similarly for both genders, the 20-item social competence scale ranges from 10 to 80, with higher scores reflecting greater perceived social competence. The social competence scale is negatively correlated with the behavior problem scales of the CBCL, which accurately distinguish clinical children with different kinds of behavior problems [11]. Correlations of 90 and higher have been reported for agreement between mothers' and fathers' ratings, and for one-week testretest reliability [13].We administered the entire instrument to obtain a valid score on the social competence scale. Coefficient alpha for this scale in our sample was .51, which is comparable to the norm sample internal consistency reliability of .60.

\section{Test of negative social exchange-revised}

The 24 item Test of Negative Social Exchange-Revised [9] estimates perceptions of communicating negative affect toward each other, negative evaluations of another, or interference with another's goal attainment, behaviors like those in [2] description of cool and withdrawn couples as well as with the contentious style of the ROCI. The present participants indicated on 10-point Likert scales (where $0=$ not at all and $9=$ frequently) how often within the past six months they experienced various negative behaviors from their spouse, such as "didn't pay attention to me," "seemed bored with me," "took my feelings lightly," and "was cold towards me."

Subscales include anger, insensitivity, manipulation, impatience, and rejection, but the high intercorrelations (.79 to .85 ) suggest that perceived negativity is more accurately described by the full-scale score [9], which ranges from 0 to 216, with higher scores indicating more perceived negative interactions. TENSE-R scores are inversely associated with support satisfaction and positively associated with depression [9]. Coefficient alpha for the full-scale score in the present sample was .85 .

\section{Rahim organizational conflict inventory-II}

The 28 items of the Rahim Organizational Conflict InventoryII (ROCI-II) delineate the respondent's self-reported conflict management style on five scales:integrating, compromising, obliging, avoiding, and dominating. The ROCI-II was designed for organizations but has been modified for other contexts [14], e.g., secondary schools, parent-child mediation, and cross-cultural research with adolescents $[13,15,16]$ using different item stems. In the present study, the sentence stem was the word spouse.

Example items include "I try to stay away from disagreements with my spouse" (avoiding) and "I negotiate with my spouse so that a compromise can be reached" (compromising). Raw scores are summed and divided by the number of items in each scale, so that all 5 scales can range from 1 to 5 , with higher scores indicating a greater tendency to use the style in question. Various studies support the validity of the ROCI-II for non-organizational settings, including the family [13].

In a study of adolescents, for example, integrating and compromising were inversely associated with engaging in physical violence and use of psychoactive substances [13]. In the current study, Cronbach alphas were integrating (.91), compromising (.81), obliging (.85), avoiding (.88), and dominating (.77).

\section{Spouse specific support scale}

The Spouse Specific Support Scale [17] has three subscales: self-esteem support (9 items), intimacy/confiding (11 items), and cohesion (15 items). The cohesion scale was omitted, as it was not relevant to the present hypotheses. Examples include "My spouse finds me interesting" (self-esteem) and "My spouse is someone I can confide in" (intimacy/confiding). The score used in this study, i.e., the sum of the self-esteem and intimacy/ confiding subscales, could range from 20 to 80, with higher scores indicating greater perceived support in the marriage.

In prior research, the self-esteem support and intimacy/ confiding subscales correlated .59 and .65, respectively, with marital satisfaction and -.47 and-.57, respectively, with marital instability Katz et al. [17]. Coefficient alphas for the present sample were .95 for self-esteem and .83 for intimacy/confiding; Combined score Cronbach's alpha for the current sample was 92.

\section{Brief COPE}

Developed from models of coping and self-regulation, the BriefCOPE (Carver, 1997) estimates the respondent's typical style of coping with stresses.When the fourteen subscales of the Brief COPE were factor analkyzed4 factors were identified:Avoidance, Acceptance, Emotion focused, and Problem focused, this scale was selected for use for two reasons. First because if the similarity between two of its scales (avoidance and problem focused) and the Katz \& Gottman's description of two conflict management styles, i.e., avoiding the problem and ignoring the problem.The second reason we selected the scale was to test the general hypothesis that responding to and managing conflict can be likened to the dynamics of the coping with stress process, and that an examination of the potential overlap of these two models would benefit each.

\section{Procedure}

Snowball sampling was used to solicit women for a study concerning "family relations." As an incentive, participants were eligible for a $\$ 100$ drawing. Packets were distributed with the measures in counterbalanced order, a cover letter, a drawing entry, and a postage-paid return envelope. The cover letter informed participants of the anonymous, voluntary nature of 
the study and directed them to consider the previous six months only in their responses.

\section{Results}

\section{Demographics}

Means and standard deviations of the major variables, presented in Table 1, were comparable to norm groups. Among the demographic variables, only years married was significantly related to children's social competence on the CBCL, $r=-.33, p$ $<01$. There were no significant correlations with this criterion variable for mother's age, race/ethnicity, educational level, work status, marital status, income, or number of children, nor for the target child's age, grade, gender or birth order. Thus, only years married was included in the major analysis as a covariate (see below).

\section{Correlational analysis}

Zero-order correlations were significant between several of the measures employed in the study (i.e., the CBCL, the SSSS, TENSE-R, the ROCI-II and the brief COPE- see Table 2), What can be characterized as sets of relationships were found between/ among subscales of the ROCI II, the SSSS, the TENS-R and CBCL. An additional set of relationships was found between the ROCIII and the COPE. As expected negativity (TENSE-R) and social support (SSSS) were inversely correlated, $(r=--.60, p<.01)$.

An acceptance coping style was negatively related to the SSSS $(\mathrm{r}=.33, \mathrm{p}<01)$, and positively related to the TENSE- $\mathrm{R}(\mathrm{r}=.47, \mathrm{p}$ $<.01)$. Similarly, an avoidant coping style was negatively related to support $\{$ SSSS $\}(r=--.50, \mathrm{p}<.01)$ and positively related to negativity (TENSE-R) $(\mathrm{r}=-.50, \mathrm{p}<.01)$.An avoidant approach to stress was also correlated negatively with \{TENSE-R\}, $(\mathrm{r}=47, \mathrm{p}$ $<.01$ ). Finally, it can be noted that an avoidant coping style was negatively related to perceived child competence as measured by the CBCL $(r=--.29, \mathrm{p}<-.29)$.

The relationships between the scales of the ROCI-II and COPE support the notion that conflict can be perceived as a normative stressor and therefore the literature on coping can be applied to that of managing conflict.Unsurprisingly the avoidant scale on the ROCI-II was positively related to the avoidant score on the COPE $(\mathrm{r}=.43, \mathrm{p}<.01$. Similarly obliging on the ROCI was positively correlated with acceptance on the COPE ( $\mathrm{r}=.23, \mathrm{P}<$ $.05)$, and avoiding ( $\mathrm{r}=.22, \mathrm{p}<.05)$.

In addition, both scales were related to the other measures used in the study, e.g., the TENSE-R, SSSS and CBCL. Specifically, an avoidant Conflict Management Style (CMS) on the ROCI-II was negatively correlated with support, $\{$ SSSS $\},(r=-.38, p<.01)$ and positively correlated with negativity, $\{$ the TENSE- $\mathrm{R}\}(\mathrm{r}=-.26, \mathrm{p}<$ .05). An obliging CMS was also negatively correlated with the TENSE- $\mathrm{R}(\mathrm{r}=-.33, \mathrm{p}<.01)$.In contrast, a compromising CMS was positively correlated with outcomes on the CBCL $(r=.25, p<.01)$ and a high integrating CMS was positively correlated with the SSSS $(\mathrm{r}=.55, \mathrm{p}<.01)$ and the CBCL $(\mathrm{r}=.26, \mathrm{p}<.05)$ but negatively correlated with the TENSE-R $(\mathrm{r}=-.46, \mathrm{p}<.01)$.
An emotional focus coping style (COPE) was positively related to both a compromising CMS $(r=22, p=.05$, and a dominating CMS ( $\mathrm{r}=28, \mathrm{p}<.01)$, while, a problem focused coping style (COPE) was positively correlated with both a compromising $(\mathrm{r}=32, \mathrm{p}<01)$ and integrating $(\mathrm{r}=31, \mathrm{p}<.01)$. These findings concerning the compromise approach to conflict management may seem contradictory, but in fact represent the reality that some compromises result after extensive contention, while other compromises result from a problem-solving orientation. Taken together these findings demonstrate the usefulness of bringing both the conflict management literature as well as the coping (with stress) literature to understand spousal conflict.

\section{Regression analysis}

Hierarchical multiple regression was used to examine the predictive power of four sets of variables: (a) years married, (b) social support and negativity (c) positive conflict resolution style (ROCI-II integrating and compromising), and (d) negative conflict resolution style (ROCI=II obliging, avoiding, and dominating) (see Table 3).At each step, the significance of the $F$ test was examined with alpha $=.05$. (b, c, \& d are "sets," but a is a single variable).

The first hierarchical regression was significant, $F(3,62)$ $=6.62, \mathrm{p}<.01$, and accounted for $24 \%$ of the variance, a nonsignificant $11 \%$ due to the covariate (years married) and a significant $13 \%(\mathrm{R} 2$ change $=.13, \mathrm{p}<.01)$ due to support and negativity. The valences of the beta weights showed that, as hypothesized, greater support, $r=.33$, and less negativity, $r=$ -.06 , were associated with greater social competence, but only support contributed uniquely to the equation, $\mathrm{t}=2.40, \mathrm{p}=.02$. When the positive and negative sets of conflict behaviors were added, $28 \%$ of the variance in social competence was accounted for, and both equations were significant, $F(5,60)=4.7, p<.01$, and $F(8,57)=2.8, \mathrm{p}<.05$, respectively.

\section{Discussion}

The results underscore [2] point that the existence of conflict per se in marriage is not necessarily a negative factor in children's social adjustment. Rather it is the quality of the relationship in which the conflict arises, and which necessarily impacts how the conflict is managed.A significant $28 \%$ of the variance in young children's social competence was accounted for by spouses' conflict management style [7,8], social support Katz et al. [2] and negativity [9], as well as one demographic factor, years married. Thus, it is a constellation of logically related (and in some cases in this study correlated) factors which determine whether marital conflict has a detrimental effect on children's social adjustment and competence.

As noted only the factor of social support uniquely contributed to the variance in children's social adjustment. but we believe that this result does not tell the whole story. As we suggested we believe it is an interactive constellation of factors which produces the overall outcome-how conflict is managed. Positive conflict resolution styles (e.g. integrating and 
compromising) both derive from and contribute to greater social support between spouses and these styles are more likely to be manifested in a context of high social support.This argument is supported by the correlational findings of a positive relationship between high SSSS and an integrative style.

In contrast relationships characterized by low social support and general negativity have been found to be characterized by negative conflict management styles.We can assume that a relationship where negative conflict management styles are used is likely to be experienced as negative and non-supportive. Here again the correlational findings support our argument with a strong negative correlation between integrating and TENSE-R. These results do not of course give us directionality of causation. We would guess they are bi-directional and they do demonstrate a relationship between the emotional tone of the relationship and the use of specific conflict styles.

From a theoretical perspective, the present results suggest that in Katz \& Gottman's [2] typology of spousal conflict behaviors, the hot and positive versus cool and withdrawn types, are based in an affective dimension which is the source of approaches to conflict management and which in turn is strengthened as the dominant dimension using specific conflict management styleseither positive or negative.That is a supportive relationship where problem solving is used, will enhance the overall sense of marital support.Similarly, the use in a negative environment of a contentious approach to conflict will likely diminish whatever support exists while increasing overall negativity.

Thus, we suggest it is this constellation of factors-general affective tone and matching conflict management styles, to which children are exposed. Thereafter, in their own social worlds, children are likely to mimic this constellation of the positive or negative emotional tone and the related overt conflict management behaviors of their parents' interactions to manage the conflict in their lives, with resulting better or worse social adjustment.As with all research there were some limitations to this study.Although our sample was somewhat diverse racially and ethnically, most participants were middle-income, married, European American women, college educated and employed outside the home-thuspotentially limiting generalizability. To control variability in parental perceptions, we limited our sample to mothers. Thus, an extension of this type of study to fathers seems important, not only because mothers and fathers may perceive their child's social adjustment differently, but also because variability in the ways men and women view the same interpersonal conflict is likely to influence child outcomes differentially.

It is possible that different results may be obtained when a different criterion is used (e.g., antisocial behavior) or when children older than age 11 are sampled.Finally, our exclusive use of self-report may have affected the results due to common method variance, distorted memory, or social desirability.
Despite these limitations, the results of this study do contribute to our understanding of the dynamics of family conflict (in this case spousal) and its impact on members of the family (in this case the children).

Importantly, the results confirm and emphasize what conflict researchers find and practitioners preach:that conflict per se is not bad but rather it is the context in which the conflict takes place (e.g., supportive versus non-supportive), the attitudes the parties have toward each other (e.g., positive versus negative) and the conflict management styles they use to address the conflict (e.g., problem-solving versus contentious) [18]. The results of this study should be of use to family conflict practitioners as a basis for understanding the dynamics of the conflicts they confront.In addition, this type of information may well be used as an educational tool-shared with parents--to help them understand the consequences of how they think about and approach marital conflict, especially in terms of the potential impact on the children exposed to their attitudes and behaviors.

\section{References}

1. Bandura A (1986) Social foundations of thought and action: A social cognitive theory. Englewood Cliffs, Prentice-Hall, Inc New Jersey, USA.

2. Katz LF, Gottman JM (1994) Patterns of marital interaction and children's emotional development. In: RD Parke, SG Kellam, et al. (Eds.), Exploring family relationships with other social contexts., $\mathrm{NJ}$ : Lawrence Erlbaum Associates, Hillsdale, USA, pp: 49-74.

3. Cummings EM, Wilson A (1999) Contexts of marital conflict and children's emotional security: exploring the distinction between constructive and destructive conflict from the children's perspective. In: Cox M, Brooks-Gunn J (Eds.), Conflict and cohesion in families Mahwah, Lawrence Erlbaum Associates, New Jersey, USA, pp: 105-129.

4. Katz LF, Gottman JM (1993) Patterns of marital conflict predict children's internalizing and externalizing behaviors. Developmental Psychology 29(6): 940-950.

5. Katz LF, Gottman JM (1995) Marital interaction and child outcomes: a longitudinal study of mediating and moderating processes. In: Parke RD, Kellam SG (Eds.), Emotion, cognition, and representation, Hillsdale, Lawrence Erlbaum Associates, New York, USA, pp: 301-342.

6. Rubin JZ, Pruitt DG, Kim SH (1994) Social conflict: escalation, stalemate, and settlement. Inc: Mc Graw-Hill, New York, USA.

7. Rahim MA (1985) A measure of styles of handling interpersonal conflict. Academy of Management Journal 26(2): 368-376.

8. Rahim MA (1987) Referent role and styles of handling interpersonal conflict. The Journal of Social Psychology 126: 79-86.

9. Finch JF, Okun MA, Pool GJ, Ruehlman LS (1999) A comparison of the influence of conflictual and supportive social interactions on psychological distress. J Pers 67(4): 581-621.

10. Achenbach TM, Edelbrock CS (1979) The child behavior profile: boys aged 12-16 and girls aged 6-11 and 12-16. J Consult Clin Psychol 47(2): 223-233.

11. Edelbrock C, Achenbach TM (1980) A typology of child behavior profile Patterns: distribution and correlates for disturbed children aged 6-16. Journal of Abnormal Child Psychology 8(4): 441-470.

12. Mc Conaughy SH (1985) Using the Child Behavior Checklist and related instruments in school-based assessment of children. School Psychology Review 14: 479-494. 
13. Van Slyck M, Stern M, Wulfert E (1998) Understanding, enhancing and assessing peace education: An attitude change approach. Paper presented to the meetings of the American Psychological Association, San Francisco, USA

14. Van Slyck MR, Stern M, Elbedour S (1999) Adolescents' beliefs about their conflict behavior: correlates, consequences, and cross-cultural issues. In: A Raviv, L Oppenheimer, D Bar-Tal (Eds.), How children understand war and peace, Jossey-Bass, USA, pp: 208-230.

15. Van Slyck M, Stern M, Zak-Place J (1996) Promoting optimal development through conflict resolution education, training, and intervention: An innovative approach for counseling psychologists The Counseling Psychologist 24(3): 433-461.

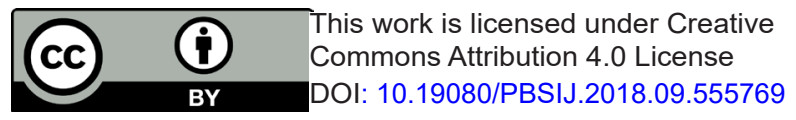

16. Stern M, Van Slyck M, Newland L (1992) Adolescent development and family dynamics: Delineating a knowledge base for family mediation. Mediation Quarterly banner 9(4): 307322.

17. Katz J, Beach SRH, Anderson P (1966) Self-enhancement versus selfverification: does spousal support always help? Cognitive Therapy and Research 20(4): 345-360.

18. Zbikowski SM, Cohen R (1996) Parent and peer evaluations of the social competence of children with mild asthma. Journal of Applied Developmental Psychology 19: 249-265.

\section{Your next submission with Juniper Publishers will reach you the below assets}

- Quality Editorial service

- Swift Peer Review

- Reprints availability

- E-prints Service

- Manuscript Podcast for convenient understanding

- Global attainment for your research

- Manuscript accessibility in different formats

( Pdf, E-pub, Full Text, Audio)

- Unceasing customer service

Track the below URL for one-step submission https://juniperpublishers.com/online-submission.php 